\title{
Multiple-Criteria Decision Analysis for Satellite Ground Stations Network Arrangement
}

\author{
Mohammad Salimi ${ }^{1}$, Mohammad Hasannia ${ }^{2}$ \\ Design and Development Office, Ground Stations Department, Iranian Space Agency, Tehran, Iran ${ }^{1,2}$
}

\begin{abstract}
In this paper, a general framework for optimum configuration of command and control satellite station will be offered according to orbital parameters of satellite. Main goal for each of command and control earth stations is to increase time period of viewing satellite and also variety of number of passes while viewing hypothetical satellites. Orbit of each satellite can be determined by main indexes known as Kepler parameters including inclination, apogee and perigee. First passes of each satellite is another main subject while determining location of stations and its index is having exact location and/or TLE of satellite in the separation point of satellite from launcher. Therefore, geographical specifications of location of satellite separation are considered for locating earth station.
\end{abstract}

Keywords: Satellite ground station, optimization, STK software, orbital parameters of satellite.

\section{INTRODUCTION}

Commanding and controlling most satellites are being In section 2 of this paper, different target functions are done through ground stations. Many parameters are offered for locating earth stations optimally and main involved in determining efficiency of earth station indexes and hypothesis would be discussed. In section 3, including orbital and telecommunication parameters [1]. general framework of suggested model would be But the most important subject for choosing location of suggested according to subjects of section 2. In section 4, earth station is access time period and/or viewing satellite specifications related to studied model would be explained then number of passes of viewing satellite from that and optimum stations would be determined according to station during satellite life. Goal of this paper is to assess different arrangements. In section 5, we will offer the arrangement and configuration of control station network summary and conclusion.

and monitoring of satellite for defined missions in LEO orbit.

So far, many articles were published about telecommunication of earth stations. But few articles assessed proper situation for establishing station and optimum arrangement of earth stations in order to reach maximum number of viewing satellite. In reference $[1,2]$ general structure of an earth station is suggested in which it is explained how to communicate between stations and satellites well. But reference [2] considered existence of earth station for satellite in urban area. In reference [3] requirements related to earth station are assessed in the time of utilization. In reference [4], it is explained how earth station of LEO works.in reference [5], applications of earth station in navigation, distance measurement and aerology are addressed. In reference [6], designing earth station and also changes are addressed that can be applied to old earth stations in order to improve its performance. References [7, 8, and 9] addressed present noises in earth stations. Reference [10] addressed optimum planning of utilization section of earth stations cooperate integrally. Reference [11] described different parameters which should be considered while constructing earth station and factors such as soil type, whether and ... are some factors have been included.

\section{Modelling}

A first method will be offered in this paper is that many stations as primary stations will be placed at desired locations aimed to host optimum arrangement of stations. Then optimization operation will be performed according to algorithm and needed constraints and limitations before best station being selected. In this section, target functions and needed constraints for selecting stations will be explained.

\section{A. Target Functions}

Many different target functions can be considered in order to locate command and control stations and the main ones are maximum time period and maximum number of viewing satellite. Next we address different target functions which are considered in this paper.

\section{a) Time Period of Viewing Satellite}

Main criterion for earth station is extent of viewing satellite. Whatever this extent be higher, efficiency of station would be increased. So, those stations are considered that time period of viewing satellite are more, there.

Calculation method: first, stations would be prioritized Most of above articles merely considered technical and telecommunication performance of earth stations but it should be noted that first proper place should be selected in order to use earth station optimally. If many stations should cooperate integrally, their optimum arrangement should be considered in order to reach maximum extent of viewing satellite.

based on viewing time. We should be aware while prioritizing stations that selected stations don't contain time overlap with earth satellite having last priority. Those stations which are at higher latitude, for example, are more suitable for orbits with inclination of 98 degree. In this way, if two stations be at same geographical longitude and latitude, then maybe will view satellite at same times and 
in this case, total viewing time wouldn't be increased and will result in lack of optimization fulfillment.

Method we follow in this paper is that first all times primary stations can view satellite would be listed in a table called "viewing satellite table" by STK software [12] then station with most viewing times would be selected as first priority. Then, times in which station view satellites would be removed from viewing table and time period of viewing by station will be calculated again and the station with next most viewing time would be selected as second priority then this cycle would be kept on. In this method indeed, stations corresponded to $\max _{T}\left\{T_{i}\right\}$ will be identified as priority after updating viewing satellite table.

\section{b) Number of Viewing Satellite}

Number of viewing satellite in certain time is considered an important index by each earth station in addition to criterion of time period of viewing. Clearly whatever number of viewing satellite be more, command and control would be performed better.

Calculation method: first, stations would be prioritized based on number of viewings in the table. Each satellite orbit enjoys different passes that total passes determines maximum number of satellite viewing. At one hand, each station can view only some of these passes. Therefore, after updating satellite viewing table, that station which is corresponded to $\max \left\{N P_{i}\right\}$ would be selected as priority but maybe as like previous condition, station has time overlap and it seems common passes should omitted. In general, omitting passes wouldn't be a good option since that maybe its time period is high and omission will waste many useful times practically. Thus, only viewing time corresponded to each priority would be omitted in order to update satellite viewing table.

\section{c) Importance of First Viewings}

One of other criterions which is important for earth stations, is to view satellite in first times after separation. In fact, we should differentiate viewing satellite in first passes and next passes. Number of viewings isn't merely a good criterion. Therefore, number of viewings index, would be replaced by viewing point index for first viewings.

Calculation method: Stations are prioritized according to time period of viewing but through point index and by mathematical function:

$$
A P_{i}=N P_{i}^{f} \cdot W^{f}+N P_{i}^{s} \cdot W^{s}
$$

In above equation, weight coefficients of $W^{s}, W^{f}$ are related to first and constant passes, respectively. In this paper, first $5 \%$ of total passes will be introduced as first passes and others as constant passes. According to above explanation, station which is corresponded to $\max \left\{A P_{i}\right\}$, would be selected as priority after updating satellite viewing table each time. There are several constraints in this optimization that will be described in continue of this paper.

\section{B. Constraints}

Location of earth station of satellite is very important for a space mission. An earth station contains different infrastructure for mutual communication of sending and receiving data by satellite. In order to optimize location of earth station, many constraints and limitations should be considered. In technical view, there are two basic conditions for earth stations (instrumentality and number of stations):

\section{a) Instrumentality of Viewing}

In each viewing by station, it should be considered this viewing must be useful. Conditions such as time of viewing and time interval between viewings are some examples.

\section{b) Number of Stations}

Building an earth station needs high cost. Therefore, simulation output should produce high efficiency by least stations. In simulation section it would be explained.

\section{III.Proposed AlgorithM}

In this section we suggest general framework of proposed model in order to determine optimum places for building earth stations. In last section, two different target functions were offered for selecting priorities including maximum total viewing time of satellite and maximum number of viewing points. But these two ways should be combined in order to determine a comprehensive algorithm for selecting stations.

\section{A. Point calculation for each station}

For each station, a total point would be introduced then the priorities will be determined based on these points. Total point can be obtained through this equation:

$$
A C_{i}=T T_{i}^{n} \cdot W^{T}+A P_{i}^{n} \cdot W^{P}
$$

In this equation, weight coefficients are $W^{P}, W^{T}$ method of viewing time period and method of viewing point, respectively. Values of $A P_{i}^{n}, T T_{i}^{n}$ are total normal time period of station $i$ and normal viewing point of station $i$ respectively. Since that viewing time period and pass point aren't of same type so should be placed at normalized state according to following equations in above equation:

$$
\begin{aligned}
T T_{i}^{n} & =\frac{T T_{i}}{\max \left\{T T_{1}, T T_{2}, \ldots, T T_{N s}\right\}} \\
A P_{i}^{n} & =\frac{A P_{i}}{\max \left\{A P_{1}, A P_{2}, \cdots, A P_{N s}\right\}}
\end{aligned}
$$

Where, Ns shows number of stations.

\section{B. Algorithm of Proposed Model}

In figure 1, proposed algorithm for locating satellite command and control earth stations optimally are shown. First according to specifications of satellite orbit and primary stations, satellite viewing table would be prepared using STK software. At next level, instrumentality of current viewings should be assessed and those which are 
not useful would be omitted from pass table. Total point For selection ideal arrangement of ground stations network for each station would be calculated and the best station in Iran, selected 150 primary stations as Figure 2. Satellite would be determined. At next level, cost-effectiveness of Characteristics that is used in STK software shown in building station should be assessed. If it be cost-effective, Figure 3. this station would be introduced as next priority. Then times in which specified station can view satellite would omitted from satellite viewing table. If station enjoy most viewing point doesn't fulfill condition of costeffectiveness then all related viewings should be omitted from the table. Determining next priority would be started by assessing instrumentality of current viewings in satellite viewing table. This process will continue until number of pass viewing table lines reach zero.

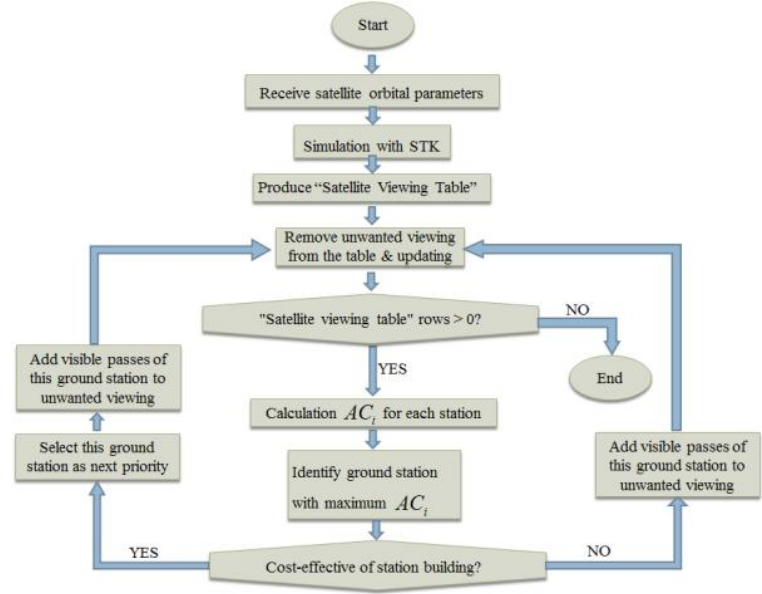

Fig.1 Diagram of proposed model for Satellite ground stations network arrangement

\section{IV.SIMULATION}

In this section, Priorities of locating satellite command and control earth stations with orbits having 55 degree inclination which usually are researcher satellites will be shown.

\section{A. Case Study}

First many stations should be created then priorities would be determined among these stations. Minimum view angle is 5 degree and since that height of antenna installation wouldn't affect satellite viewing extent, it is ignored. Table I shows weight coefficients used in simulation.

TABLE I: WEIGHT COEFFICIENTS USED IN SIMULATION

\begin{tabular}{|c|c|c|c|}
\hline$W^{s}$ & $W^{f}$ & $W^{P}$ & $W^{T}$ \\
\hline 0.4 & 0.6 & 0.5 & 0.5 \\
\hline
\end{tabular}

One of other conditions applied in this paper, is at least one time interval dedication between two consecutive viewings in final stations set. In simulation, 30 minutes time interval is considered between two consecutive viewings.

Duration of mission is 30 days and conditions of viewing instrumentality and minimum time of 180 seconds are considered for each viewing. Cost-effectiveness of building station is presented so that during mission at least can view satellite totally 2500 seconds. It means that each station without considering time of common viewing with other stations have at least 2500 seconds viewing ability.

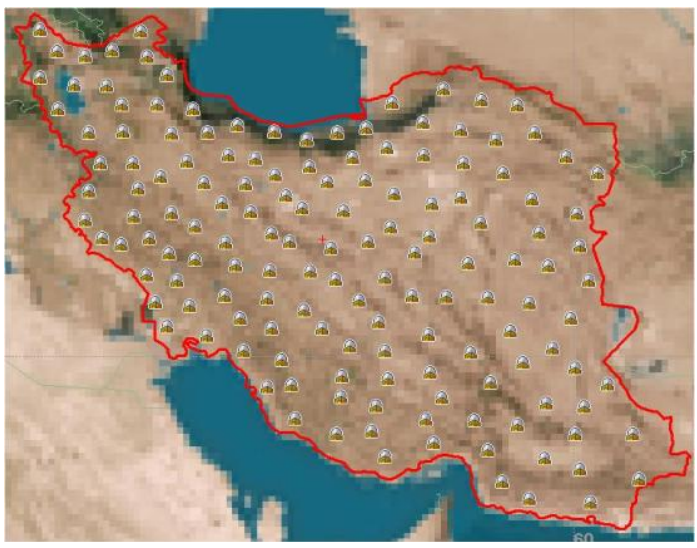

Fig.2 Selected Primary Stations

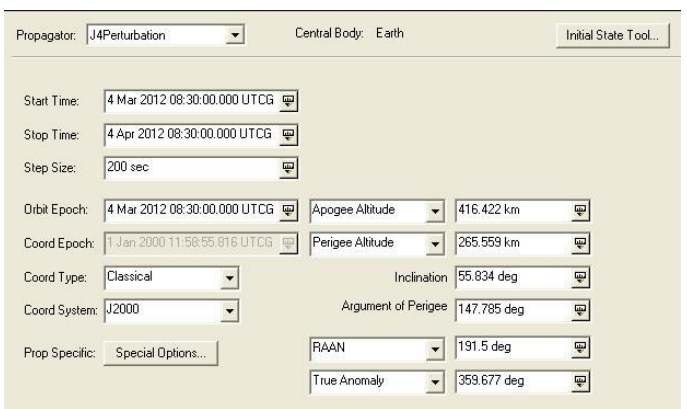

Fig.3 Specifications of Satellite

\section{B. simulation results}

The ideal arrangement in ground stations network is shown in Figure 4. As can be seen, the first priority is the highest latitude corresponding to nearest station located at latitude 55 degrees. By removing time viewing of this ground station and updating the "satellite viewing table", second priority located to the extreme south-eastern Iran. By continuing this process, two other stations will be select. Then there are no optimal stations. Number and total time period of satellite viewing by Ideal arrangement shown in Table II and Figure 5.

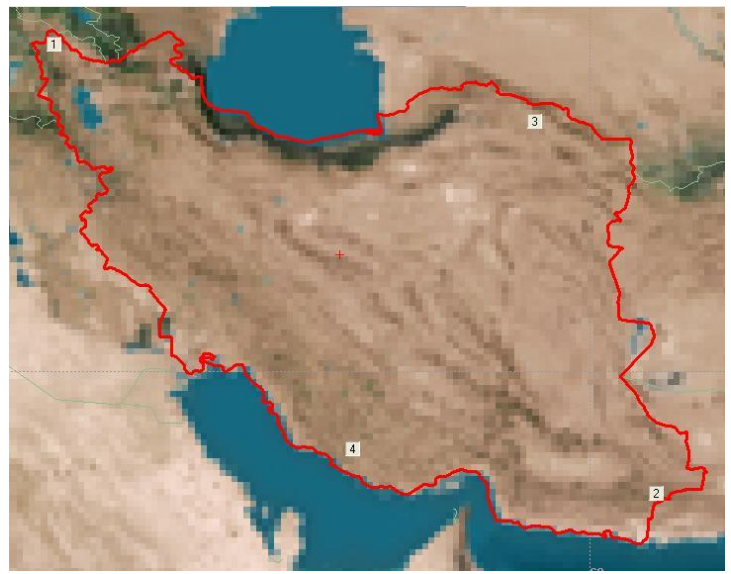

Fig.4 Ideal arrangement of satellite ground stations 
TABLE II: NUMBER AND TOTAL TIME PERIOD OF SATELLITE VIEWING INIDEAL ARRANGEMENT

\begin{tabular}{|c|c|c|}
\hline Priority & $\begin{array}{c}\text { total time period of } \\
\text { satellite viewing (s) }\end{array}$ & $\begin{array}{c}\text { Percent Visibility } \\
(\%)\end{array}$ \\
\hline 1 & 52528.64 & 61 \\
\hline 2 & 26748.14 & 31 \\
\hline 3 & 4110.257 & 5 \\
\hline 4 & 2657.905 & 3 \\
\hline 5 & 709 & \\
\hline
\end{tabular}

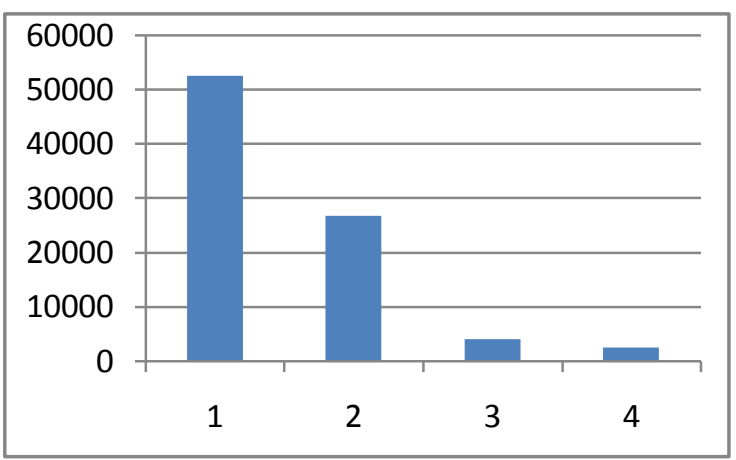

Fig.5 Total time period of satellite viewing by each station

\section{CONCLUSION}

Assessment for locating earth stations in addition to determine comprehensive plan for space mission development; will plan performing levels of building command and control earth station of satellites. Thus in this paper, comprehensive model is offered for optimally locating satellite ground stations. Basic criterions for selecting location of each station have been time period of viewing, number of viewing, valuing first passes and also variety of satellite passes. In fact, using orbital parameters, optimal place of stations were determined and their configuration was located.

\section{REFERENCES}

[1] Maral, G. and Bousquet, M., "Satellite Communication Systems," John Willey sons, Inc, 4th ed, 2005

[2] Cakaj, Shkelzen, and KrešimirMalarić. "Rigorous analysis on performance of LEO satellite ground station in urban environment" International Journal of Satellite Communications and Networking 25.6 (2007): 619-643.

[3] Elbert, Bruce R. "The Satellite Communication Ground Segment and Earth Station Handbook." Artech House, 2006.

[4] Vangli, Henning. "Construction of a remotely operated satellite ground station for low earth orbit communication" Diss. Master's thesis, University of Oslo, Department of Physics, 2010.

[5] Madry, Scott, Joseph N. Pelton, and Sergio Camacho-Lara. "Ground Systems for Satellite Application Systems for Navigation, Remote Sensing, and Meteorology." Handbook of Satellite Applications. Springer New York, 2013. 1095-1110.

[6] Mishra, Raj Gaurav. "Development of a Ground Station (GS) Package Suited for Spacecraft Operation Control and Optimization for Satellite Flyby over the Ground Station." HCTL Open Publications Solutions, India, 2014.

[7] S. CAKAJ, "Rain Attenuation Impact on Performance of Satellite Ground Stations for Low Earth Orbiting (LEO) Satellites in Europe," Int'l J. of Communications, Network and System Sciences, Vol. 2 No. 6, 2009, pp. 480-485

[8] Cakaj, S.; Malaric, K., "Composite Noise Temperature at Low Earth Orbiting Satellite Ground Station," Software in Telecommunications and Computer Networks, 2006. SoftCOM
2006. International Conference on, vol., no., pp.214,217, Sept. 29 2006-Oct. 12006

[9] Cakaj, S.; Keim, Werner; Malaric, K., "Sun noise measurement at low Earth orbiting satellite ground station," ELMAR, 2005. 47th International Symposium, vol., no., pp.345,348, 8-10 June 2005.

[10] Xhafa, Fatos, et al. "Evaluation of struggle strategy in Genetic Algorithms for ground stations scheduling problem.” Journal of computer and system sciences79.7 (2013): 1086-1100.

[11] Angepat, S., "Ground Station Selection and Feasibility Analysis, "CARLETON UNIVERSITY SPACECRAFT DESIGN PROJECT, 2005

[12] STK Comprehensive, Version 10. [Online]. Available: http://www.agi.com/downloads/resources/EAP/STKComprehensive

\section{BIOGRAPHIES}

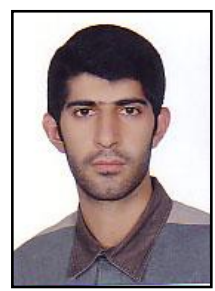

Mohammad Salimi is currently working as a researcher and expert in design and development of satellite ground segment at, Iranian space agency. He received his B.S. and M.S. both in electrical engineering from University of Guilan, Rasht, Iran in 2009, and University of Tehran, Tehran, Iran in 2012, respectively. His research interests are ground station systems, space solar power, wireless energy transfer and optimization.

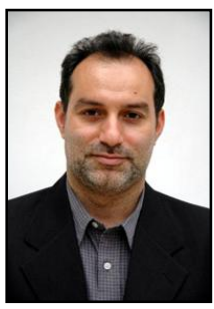

Mohammad Hasannia is currently working as a manager in design and development of ground stations office at, ground stations department, deputy of Space Application \& Services, Iranian space agency. He received his B.S. in communications engineering degree from KhajeNasirToosi University of Technology, Tehran, Iran in 1989 and M.S. in wave field from Tehran Azad University, Tehran, Iran in 1992.He served as a lecturer at the Azad Universityfor several years. He is doing minor research works on various fields like ground station systems, space communications link budgets, wireless communications, rectifier antenna and star sensors. 